\title{
Effects of Reinnervation of the Biarticular Shoulder-Elbow Muscles on Joint Kinematics and Electromyographic Patterns of the Feline Forelimb during Downslope Walking
}

\author{
Beven P. Livingston T. Richard Nichols \\ Emory University, Atlanta, Ga., USA
}

\section{Key Words}

Electromyographic patterns · Forelimb - Joint kinematics · Locomotion · Nerve injury

\begin{abstract}
Full recovery of the forelimb kinematics during level and upslope walking following reinnervation of the biarticular elbow extensor suggests that the proprioceptive loss is compensated by other sensory sources or altered central drive, yet these findings have not been explored in downslope walking. Kinematics and muscle activity of the shoulder and elbow during downslope locomotion following reinnervation of the feline long head of the triceps brachii (TLo) and biceps brachii ( $\mathrm{Bi}$ ) were evaluated (1) during paralysis and (2) after the motor function was recovered but the proprioceptive feedback was permanently disrupted. The step cycle was examined in three walking conditions: level $(0 \%),-25 \%$ grade $\left(-14^{\circ}\right.$ downslope) and $-50 \%$ grade $\left(-26.6^{\circ}\right.$ downslope). Measurements were taken prior to and at three time points ( 2 weeks, and 1 and $12+$ months) after transecting and suturing the radial and musculocutaneous nerves. There was an increase in the yield (increased flexion) at the elbow and less extensor activity duration of flexion during stance as the downslope grade increased. There were two notable periods of eccentric contractions (active lengthening) providing an apparent 'braking' action. Paralysis of the TLo and the Bi re-
\end{abstract}

sulted in uncompensated alterations in shoulder-elbow kinematics and motor activity during the stance phase. However, unlike the case for the level and upslope conditions, during both paralysis and reinnervation, changes in interjoint coordination persisted for the downslope condition. The lack of complete recovery in the long term suggests that the autogenic reflexes contribute importantly to muscle and joint stiffness during active lengthening.

(c) 2015 S. Karger AG, Basel

\begin{tabular}{ll}
\hline Abbreviations used in this paper \\
\hline $\mathrm{Bi}$ & biceps brachii \\
$\mathrm{Br}$ & brachialis \\
$\mathrm{ClB}$ & cleidobrachialis \\
$\mathrm{E} 1$ & first extension of the elbow/shoulder \\
$\mathrm{E} 2$ & elbow/shoulder flexion during stance (yield) \\
$\mathrm{E} 3$ & second extension of the elbow/shoulder \\
EMG & electromyographic \\
$\mathrm{PC}$ & paw contact \\
$\mathrm{P} 1 \mathrm{mo}$ & 1 month after surgery \\
P12+mos & $>12$ months after surgery \\
$\mathrm{P} 2 w \mathrm{ks}$ & 2 weeks after surgery \\
PO & paw off \\
TLa & lateral head of the triceps \\
TLo & long head of the triceps brachii \\
TM & medial head of the triceps
\end{tabular}

\section{KARGER}

E-Mail karger@karger.com

www.karger.com/cto
(C) 2015 S. Karger AG, Basel

1422-6405/15/1996-0423\$39.50/0
Beven P. Livingston

University of North Florida

1 UNF Drive

Jacksonville, FL 32224-7699 (USA)

E-Mail b.livingston@unf.edu 


\section{Introduction}

The assessment of different forms of quadrupedal walking in the cat has provided remarkable insight into the function of different skeletal muscles and the neural mechanisms required for the motor control of locomotion [Buford and Smith, 1990; Fowler et al., 1993; Rossignol, 1996; Trank and Smith, 1996; Trank et al., 1996; Zernike and Smith, 1996; Stein et al., 1997; Carlson-Kuhta et al., 1998; Smith et al., 1998; Gregor et al., 2001; Kaya et al., 2005; Maas et al., 2005]. It has been suggested that the physical demands of slope walking differ significantly during downslope compared to level and upslope walking. During level quadruped locomotion, the vertical ground reaction forces are higher for the forelimb than the hindlimb [Prilutsky et al., 2005] because the center of mass of the animal is closer to the forelimb [Manter, 1938; Alexander, 1980; Pandy et al., 1988]. Because of the higher forelimb forces, the peak joint moments are also greater for the forelimb versus the hindlimb. Among the forelimb joints, the elbow is thought to contribute the most to power generation and propulsion during stance as compared to the ankle joint in the hindlimb [Prilutsky et al., 2005]. Although there have been no kinematic or kinetic studies of the forelimb during downslope walking reported in the literature, it was suggested that the forelimb provides only a braking force (power absorption) for most if not all of the stance phase [Smith et al., 1998]. Furthermore, studies have concentrated on the role of one- and two-joint muscles with the notion that control systems may be organized around the mechanical actions of muscles and the number of joints they span [Nichols, 1994].

In the hindlimb, animals did not fully compensate for motor deficits observed during downslope walking following paralysis and reinnervation of the anti-gravity triceps surae muscles [Abelew et al., 2000; Maas et al., 2007; Chang et al., 2009]. However, compensation was observed during level and upslope walking following paral$y$ sis and reinnervation of the different components of the triceps surae muscles [Abelew et al., 2000; Maas et al., 2007; Chang et al., 2009] in the hindlimb and in the long head of the triceps brachii (TLo) [Livingston et al., 2002] of the forelimb. It was concluded in the companion paper [Livingston and Nichols, 2015] that following reinnervation of the biarticular elbow extensor (TLo), recovery of the shoulder-elbow joint kinematics and muscle activity during level and upslope locomotion returned to baseline, suggesting that the proprioceptive loss is compensated by other sensory sources or altered central drive.
Since downslope walking appears particularly demanding for muscles of the forelimb, reinnervation of the biarticular shoulder-elbow muscles provides an additional opportunity to further understand the role of sensory feedback and muscular redundancy.

The first aim of this report was to document for the first time the joint kinematics and electromyographic (EMG) activation patterns of the feline forelimb during downslope locomotion. The second aim was to document the effects of paralysis and reinnervation of the TLo and biceps brachii ( $\mathrm{Bi}$ ) on joint kinematics and EMG of the shoulder and elbow during downslope walking in the cat. This is the first systematic report in which the short- and long-term effects of reinnervation on forelimb gait kinematics and EMG activation patterns have been assessed. This study is the second part of a larger project which investigated the effects of reinnervation of feline TLo and Bi muscles on joint kinematics and EMG during other mechanically challenging tasks, including visually guided reaching. Preliminary results on joint kinematics and EMG activity have been presented in abstract form [Livingston et al., 2002, 2004; Livingston and Nichols, 2005].

\section{Methods}

The methods used here were similar to those described in the companion paper [Livingston and Nichols, 2015], so only a summary is provided here along with procedures specific to the study of downslope walking.

\section{Animal Care and Training}

All surgical and experimental procedures were consistent with the US Public Health Service Policy on Humane Care and Use of Laboratory Animals and according to the Guidelines for Research Involving Animals and were approved by the Institutional Animal Care and Use Committee of Emory University. All cats were housed in one large room of adequate space with access to food and water ad libitum. Six laboratory cats [Felis domesticus: 6 males (4.7-7.1 kg, average: $5.5 \mathrm{~kg}$ )] were trained for 3 months to walk on a walkway $(2.7 \times 0.33 \mathrm{~m})$. The walkway was declined to one of three different grades: $0 \%$ (level), $-25 \%\left(-14^{\circ}\right.$ slope $)$ and $-50 \%\left(-26.6^{\circ}\right.$ slope). Thirty trials were recorded at each grade before surgery. There was no further training following the reinnervation surgery.

\section{Surgical Reinnervation}

All 6 cats were used for the surgical reinnervation procedure ( $n=3$ for TLo reinnervation and Bi reinnervation, respectively). Following surgery, the cats were placed in individual cages and closely monitored while they recovered. Once they were able to eat, stand and use the litter box, they were returned to the colony to walk, run, jump, climb and interact with the other cats. Data collection was initiated about 2-4 weeks after they had recuperated. The cats were allowed 13-36 months of recovery from the date of surgery. 
Surgical EMG Implants

Sterile surgical procedures were used for implanting EMG electrodes in all 6 cats. In 2 of the 6 cats, EMG electrodes were implanted approximately 12 months after reinnervation surgery. After each surgery, the cats recovered in an individual cage and were returned to an isolated colony in $24-48 \mathrm{~h}$. Data collection was initiated about 2 weeks after the animals had recuperated.

\section{Assessment of Reflexes after Surgical Reinnervation}

After collecting all the kinematic and EMG data, the effects of TLo and Bi reinnervation on the integrity of the autogenic and heterogenic reflex pathways of the reinnervated muscles were assessed using the methods described by Nichols [1989, 1999].

\section{Data Analysis}

Kinematics

Each cat was tested in 3 series of experiments, i.e. (1) before reinnervation surgery, (2) 2 weeks (P2wks) and 1 month (P1mo) after surgery (short term) and (3) $>12$ months after the surgery (P12+mos; long term), and in three locomotion conditions, i.e. level, and $-25 \%$, and $-50 \%$ downslope grades. Please refer to the Methods section under Kinematics for the procedures in the companion paper [Livingston and Nichols, 2015]. One trial consisted of a complete step which was selected from the middle of a series of steps to avoid changes in acceleration. Paw off (PO) and paw contact (PC) were identified visually from the digitized images. Step cycle phases for the shoulder and elbow were identified according to Philippson [1905]. All joint kinematic data were time normalized. Plots of joint angle as a function of time and as a function of joint angle were created to calculate the differences in shoulder and elbow temporal and angular kinematic variables for each step cycle.

\section{EMG Data}

The EMG signals were amplified with a gain of 1,000 and synchronized with the video via a voltage trigger. A custom computer program written in LabVIEW version 7.1 digitally converted the EMG signal at a sampling rate of $4 \mathrm{kHz}$ and then it was stored on a PC. The EMG files were then clipped in synchrony with the digital video $(125 \mathrm{~Hz})$ for a complete step cycle and converted to MATLAB files. The data were then analyzed using custom MATLAB software. The signals were bandpass filtered between 20 and $500 \mathrm{~Hz}$ with a 4th-order Butterworth filter (see Methods section of Livingston and Nichols [2015] for more details).

\section{Mechanographic Analysis}

The contribution of feedback from muscle receptors was detected using a mechanographic technique [Nichols, 1987]. Please refer to the Methods section under Mechanographic Analysis for the procedures in Livingston and Nichols [2015].

\section{Statistics}

To compare various kinematic and EMG parameters for downslope walking both before and after surgery, repeated-measure analysis of variance in conjunction with a general-linear model (Statistical Package for the Social Sciences, SPSS ${ }^{\circledR}$ version 14.0 for Windows) was used. A Tukey's post hoc test was used to test differences between cell means. Statements indicating a quantitative difference between data sets are based on a significance level of $\mathrm{p} \leq 0.05$.

Effects of Reinnervation of Feline Elbow Muscles during Downslope Walking
Table 1. Step cycle, stance and swing duration (in $\mathrm{ms}$ ) at $0,-25$ and $-50 \%$ grade

\begin{tabular}{llll}
\hline & $0 \%$ & $-25 \%$ & $-50 \%$ \\
\hline $\begin{array}{lll}\text { Control } \\
\text { Cycle period }\end{array}$ & $613 \pm 82$ & $575 \pm 92$ & $590 \pm 92$ \\
Stance period & $397 \pm 75$ & $358 \pm 87$ & $369 \pm 91$ \\
Swing period & $216 \pm 18$ & $217 \pm 21$ & $221 \pm 20$ \\
\hline P2wks & & & \\
Cycle period & $637 \pm 82$ & $640 \pm 97$ & $652 \pm 90$ \\
Stance period & $427 \pm 80$ & $438 \pm 82$ & $443 \pm 95$ \\
Swing period & $210 \pm 23$ & $202 \pm 21$ & $209 \pm 22$ \\
\hline P1mo & & & \\
Cycle period & $638 \pm 94$ & $630 \pm 97$ & $647 \pm 98$ \\
Stance period & $426 \pm 89$ & $422 \pm 90$ & $433 \pm 99$ \\
Swing period & $212 \pm 21$ & $208 \pm 15$ & $214 \pm 13$ \\
\hline P12+mos & & & \\
Cycle period & $612 \pm 68$ & $605 \pm 70$ & $622 \pm 94$ \\
Stance period & $408 \pm 51$ & $400 \pm 79$ & $420 \pm 90$ \\
Swing period & $204 \pm 15$ & $205 \pm 13$ & $202 \pm 14$ \\
\hline
\end{tabular}

Values are means \pm SD for control ( $n=6$ cats), P2wks ( $n=3$ cats), $P 1 \mathrm{mo}(\mathrm{n}=3$ cats $)$ and $\mathrm{P} 12+\operatorname{mos}(\mathrm{n}=3$ cats $)$ time points. $\mathrm{n}=$ 10-30 steps/grade.

\section{Results}

\section{Comparison of Level and Downslope Locomotion}

Kinematics

Means and standard deviations of the stance, swing, and step cycle duration are reported for 3 cats (JU2b, WL6b and SM4b) during the denervation-reinnervation trials in table 1 . Step cycle periods were all within the range of 400-900 ms, which is consistent with moderate walking speed [Smith et al., 1993]. There was no significant difference in average walking speeds with grade. However, although not statistically significant, the greatest variability in speed was across cats; therefore, in order to reduce the possibility that speed-related differences would be confounded with slope-related differences, each cat served as its own control for the presentation of the kinematic and EMG data.

Exemplar joint angle-time plots for the shoulder and elbow are illustrated in figure $1 \mathrm{a}, \mathrm{b}$. In tables 2 and 3 , the mean shoulder and elbow joint positions during each step cycle transition are listed. At all three grades of walking, the pattern of angular displacement for the shoulder and elbow joints was consistent for all 6 cats. 


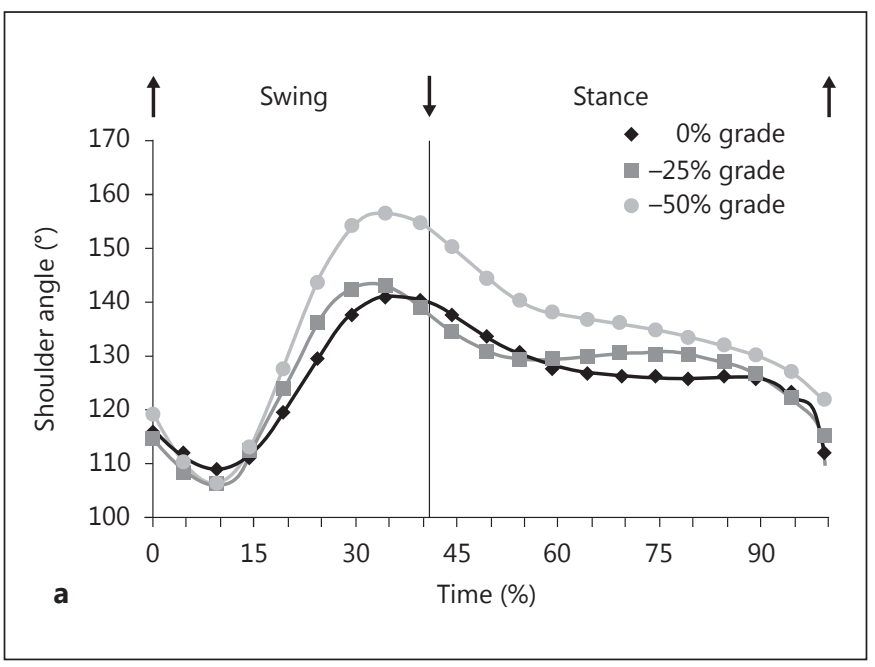

Fig. 1. a, b Joint angle-time plot for the shoulder (a) and elbow joint (b) during level (0\% grade) and downslope ( -25 and $-50 \%$ grade) walking for cat JU2b. Values are the means of 30 time-normalized steps. The graph begins and ends with $\mathrm{PO}(\uparrow)$ and between them is PC $(\downarrow)$ of the step cycle. c Shoulder-elbow angle-angle plots for level ( $0 \%$ grade) and downslope ( -25 and $-50 \%$ grades) walking for cat SL5t. Values are the time-normalized averages from 30 steps. For each cyclograph, the step cycle starts and ends with PO and reads in a clockwise direction. Stance phase is marked with the dashed lines and swing is marked with solid lines. Data points are plotted for each frame (8-ms intervals).

\section{Swing}

Common to all slope conditions (fig. 1) [figure 2 in Livingston and Nichols, 2015], the elbow and shoulder exhibited generally similar kinematics, including flexion followed by the first extension (E1), but different trends as the slopes changed. The extension during late swing (E1) increased for the steepest downslope, in contrast to upslope walking where it decreased with slope [figure 2 in Livingston and Nichols, 2015]. Other features included greater flexion for the elbow than shoulder, specifically during $\mathrm{PO}$ at $-50 \%$ grade, and a phase advance of the transition between flexion and $\mathrm{E} 1$ at the shoulder compared to that at the elbow (fig. 1a, b).

\section{Stance}

At the $-50 \%$ grade, the shoulder and elbow joints were significantly more extended at PC (tables 2, 3). During
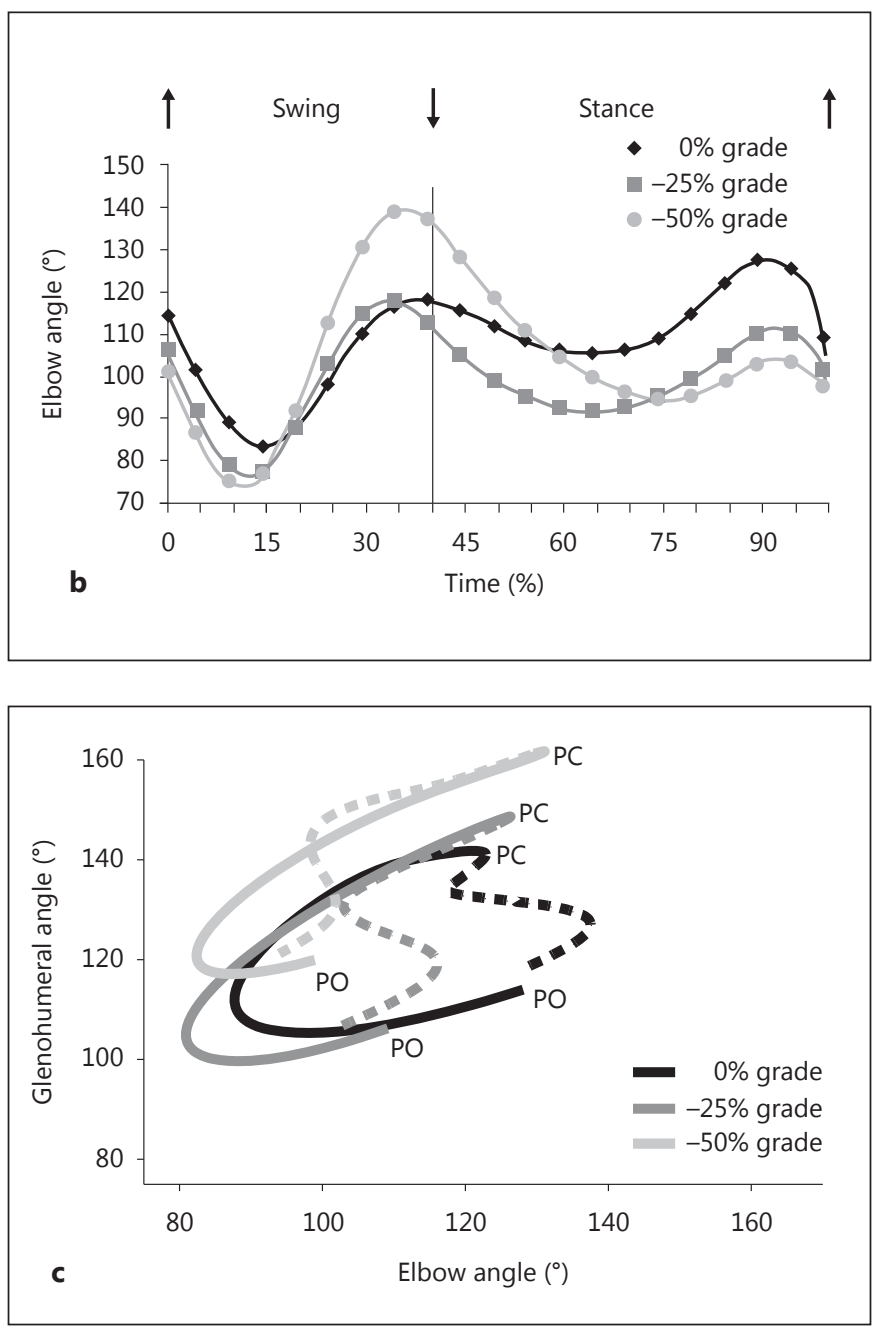

elbow flexion during stance (E2) of the $-50 \%$ grade, the elbow joint's angular excursion ('yield', i.e. flexion) was significantly larger than during level walking (fig. 1). Two other key features were that during the second elbow extension (E3) of the stance phase of declining walking, the shoulder is flexing and the elbow is extending, and at peak extension, the elbow position was significantly more flexed than during level walking (tables 2, 3).

\section{Interjoint Coordination}

Changes in interjoint coordination between the shoulder and elbow joints were assessed by angle-angle plots (cyclographs; fig. 1c). The shift in the cyclograph to the upper left corner of the graph indicates an out-of-phase shift between shoulder joint extension and elbow joint flexion as the steepness of downslope walking increased. During swing, there was a decrease in angular excursion 
Table 2. Angular positions (in ${ }^{\circ}$ ) of the forelimb shoulder and elbow joints at step cycle transitions for the TLo denervation/reinnervation

\begin{tabular}{|c|c|c|c|c|c|c|c|c|c|}
\hline & \multicolumn{9}{|l|}{ Time } \\
\hline & $0 \%$ & $-25 \%$ & $-50 \%$ & $0 \%$ & $-25 \%$ & $-50 \%$ & $0 \%$ & $-25 \%$ & $-50 \%$ \\
\hline \multicolumn{10}{|c|}{ Shoulder } \\
\hline PO & $114 \pm 8$ & $106 \pm 5$ & $108 \pm 7$ & $130 \pm 3^{b}$ & $107 \pm 4$ & $106 \pm 4$ & $118 \pm 4$ & $103 \pm 3$ & $95 \pm 5^{\mathrm{d}}$ \\
\hline $\mathrm{F}-\mathrm{E} 1$ & $105 \pm 16$ & $98 \pm 7$ & $101 \pm 6$ & $125 \pm 2^{b}$ & $104 \pm 4$ & $103 \pm 3$ & $113 \pm 3$ & $95 \pm 4$ & $94 \pm 5^{d}$ \\
\hline E2-E3 & $127 \pm 18$ & $108 \pm 9$ & $111 \pm 4$ & $136 \pm 10$ & $110 \pm 6$ & $106 \pm 5$ & $121 \pm 6$ & $102 \pm 2$ & $97 \pm 3$ \\
\hline Peak E & $129 \pm 19$ & $108 \pm 9$ & $111 \pm 4$ & $136 \pm 11$ & $110 \pm 6$ & $106 \pm 5$ & $121 \pm 6$ & $102 \pm 2$ & $97 \pm 3$ \\
\hline \multicolumn{10}{|l|}{ Elbow } \\
\hline $\mathrm{PO}$ & $128 \pm 8$ & $109 \pm 17$ & $101 \pm 15^{\mathrm{a}}$ & $120 \pm 9$ & $105 \pm 7$ & $87 \pm 4^{\mathrm{c}}$ & $124 \pm 10$ & $116 \pm 8$ & $84 \pm 4^{\mathrm{d}}$ \\
\hline $\mathrm{F}-\mathrm{E} 1$ & $86 \pm 14$ & $77 \pm 5$ & $75 \pm 5$ & $92 \pm 5$ & $87 \pm 5$ & $76 \pm 3$ & $93 \pm 7$ & $84 \pm 5$ & $75 \pm 2$ \\
\hline
\end{tabular}

Values are means \pm SD from 10-30 steps per grade for 2 cats (SP1t and SL5t). F-E1 = Swing flexion-extension reversal; Peak E = stance phase peak extension. ${ }^{\mathrm{a}} \mathrm{p} \leq 0.05,{ }^{\mathrm{b}} \mathrm{p} \leq 0.05$ vs. $0 \%$ control; ${ }^{\mathrm{c}} \mathrm{p} \leq 0.05,{ }^{\mathrm{d}} \mathrm{p} \leq 0.05 \mathrm{vs} .-50 \%$ control.

Table 3. Angular positions (in ${ }^{\circ}$ ) of the forelimb shoulder and elbow joints at step cycle transitions for Bi denervation/reinnervation

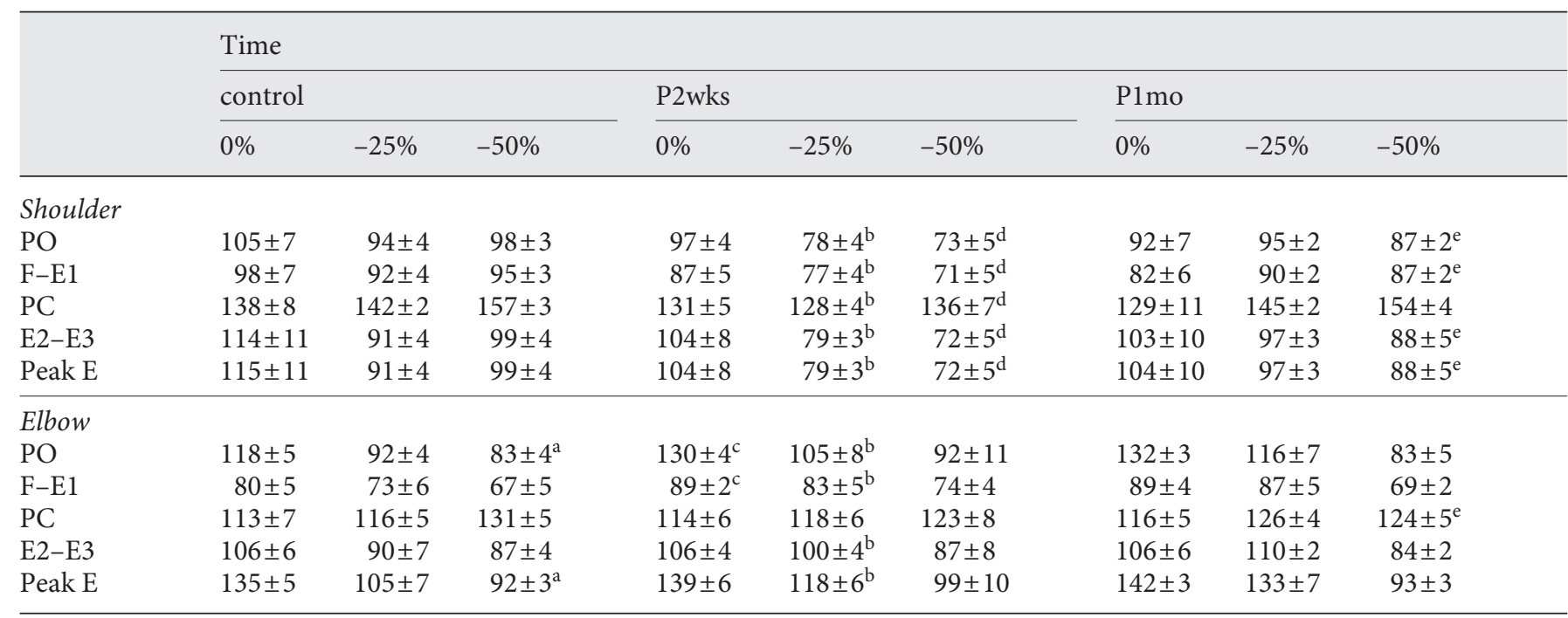

Values are means \pm SD from 10-30 steps per grade for 2 cats (JU2b and WL6b). F-E1 = Swing flexion-extension reversal; Peak E = stance phase peak extension. ${ }^{\mathrm{a}} \mathrm{p} \leq 0.05$ vs. $0 \%$ control; ${ }^{\mathrm{b}} \mathrm{p} \leq 0.05 \mathrm{vs} .-25 \%$ control; ${ }^{\mathrm{c}} \mathrm{p} \leq 0.05 \mathrm{vs} .0 \%$ control; ${ }^{\mathrm{d}} \mathrm{p} \leq 0.05,{ }^{\mathrm{e}} \mathrm{p} \leq 0.05 \mathrm{vs} .-50 \%$ control.

by the elbow joint at the $-50 \%$ grade during flexion as compared to level walking and a more extended shoulder position during E1. This was in sharp contrast to the $50 \%$ upslope locomotion [figure 2c in Livingston and Nichols, 2015].

Effects of Reinnervation of Feline Elbow Muscles during Downslope Walking
Contour changes in the shoulder-elbow cyclographs during the stance phase were also related to the grade of downslope walking. During level walking, there was a positive slope during E2 indicating the two joints were flexing together (fig. 1c). During downslope walking, un- 


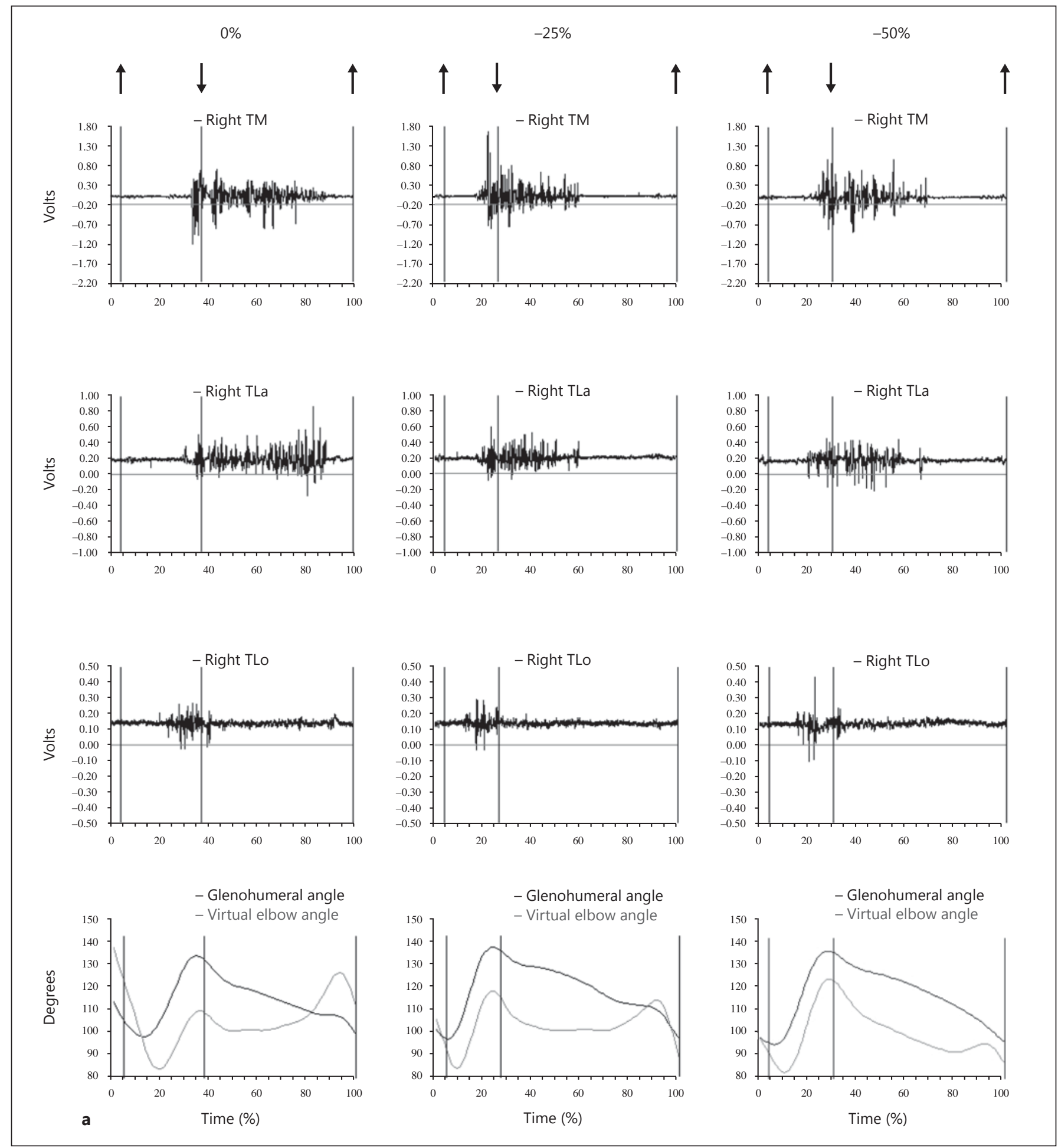

Fig. 2. Raw EMG records from the elbow extensors (a) and flexor muscle group (b) from a representative step cycle for level and downslope walking for cat WL6b. $\uparrow=\mathrm{PO} ; \downarrow=\mathrm{PC}$.

(For figure $2 b$ see next page.) 


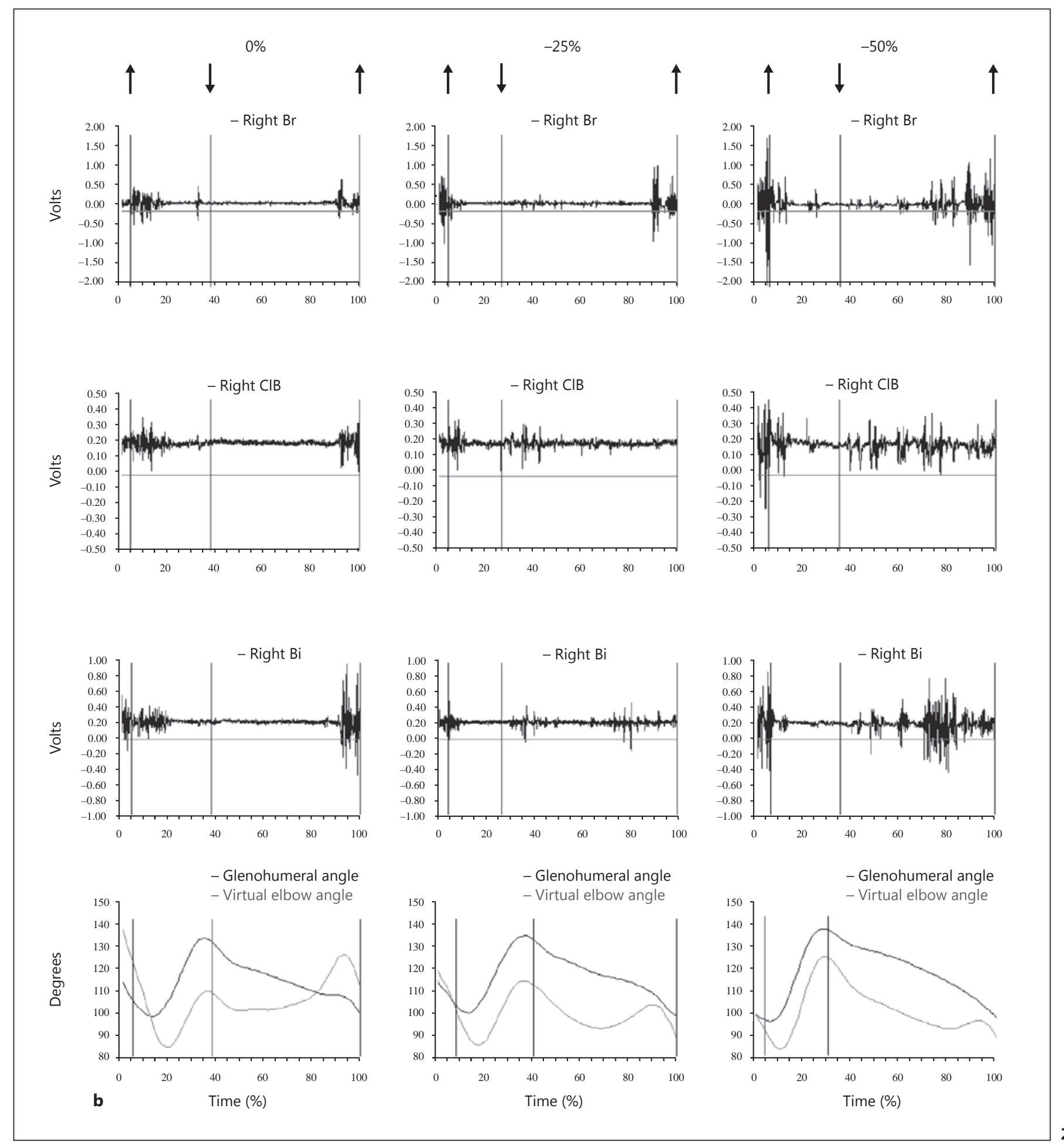




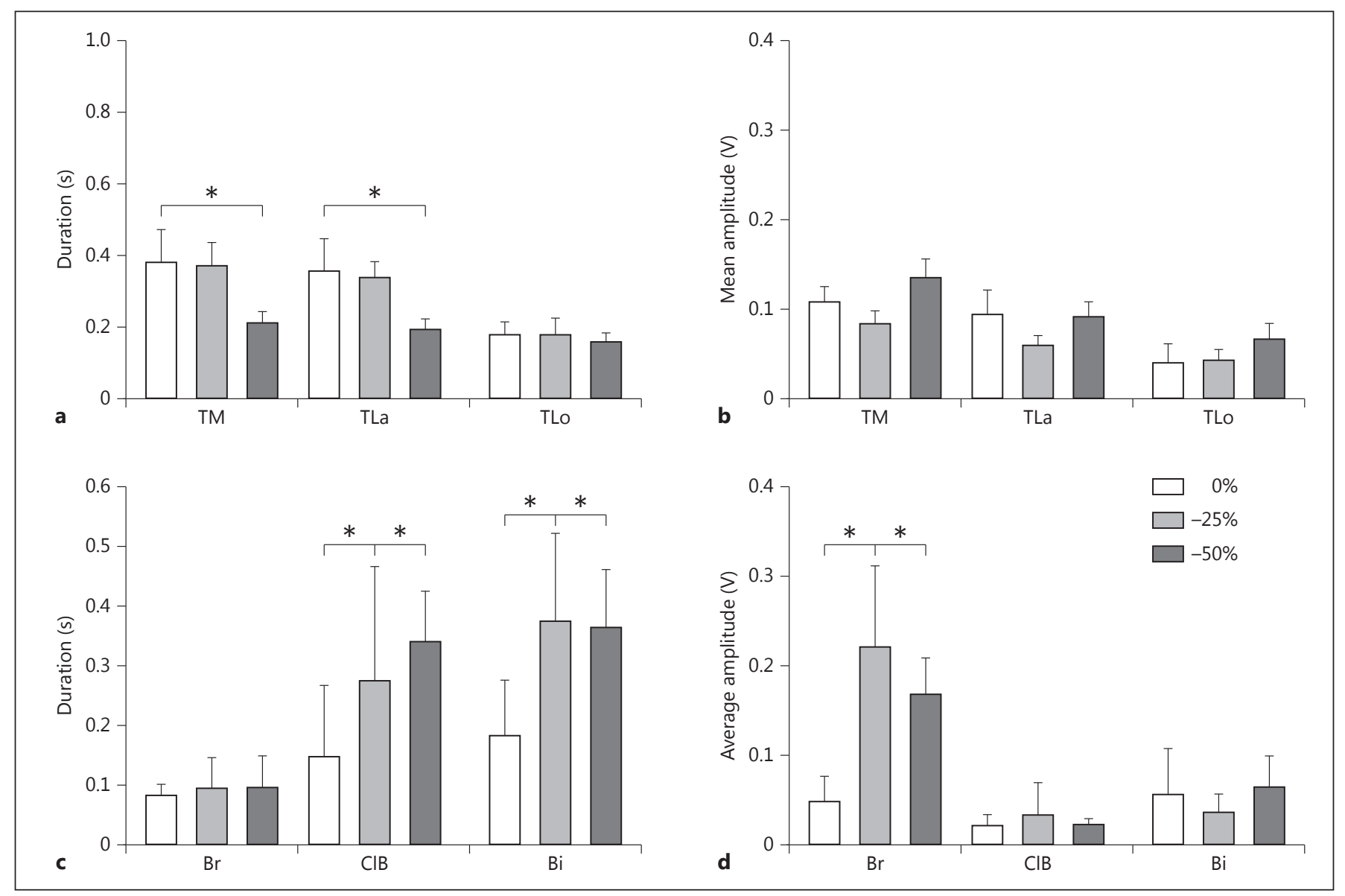

Fig. 3. Comparison of control EMG burst duration and average amplitude of the extensor muscles (cat NO3t) and the elbow flexors (cat $\mathrm{JU} 2 \mathrm{~b}$ ) for level and downslope walking. Values are the means \pm SD of 30 steps. a, c Burst duration. b, d Mean burst amplitude. $* \mathrm{p} \leq 0.05$.

like upslope walking [figure 2 in Livingston and Nichols, 2015], the slope during E2 was also positive, indicating the two joints were flexing together. The slope-related changes in the shoulder-elbow graphs during E3 (from the E2-E3 transition to peak extension) were also related to the increasing steepness of the downslope walking (fig. 1c). The slopes of the cyclographs during E3 at all grades were negative indicating the elbow joint was extending and the shoulder joint flexing. However, during E3 phase of $-50 \%$ downslope walking, the slope of the angle-angle plots became less negative (more vertical) indicative of less elbow joint extension.

\section{Comparison of Motor Patterns of Select Shoulder and} Elbow Muscles during Downslope Walking

Typical EMG traces illustrate the activity of the elbow extensors (fig. 2a) and the elbow flexors (fig. 2b) for both level and downslope walking.
The two monoarticular muscles, the medial (TM) and lateral head of the triceps (TLa), with extensor function at the elbow joint had predominantly stance-related activity. The activity began just prior to PC during E1 and continued for approximately $50 \%$ of stance during the two downslope conditions (fig. 2a). This is a period of active lengthening for these muscles as the elbow joint was flexing during the stance-related activity. The duration of these elbow extensor bursts decreased significantly from level to $-50 \%$ grade (fig. 3a). From level to the $-50 \%$ grade, TM and TLa changed in burst duration from 386 \pm 95 to $212 \pm 30$ and from $370 \pm 99$ to $193 \pm 28 \mathrm{~ms}$, respectively. The average burst amplitude and peak amplitude of these two monoarticular elbow muscles did not change with the steepness of the slope (fig. 3b). This was in contrast to the upslope condition (companion paper) where the average and peak amplitudes increased with slope. 
The activity of the biarticular muscle (TLo) with extensor function at the elbow joint and flexor function at the shoulder joint began during E1 of swing and continued for only the early portion of the stance (fig. 2a). There was no change in burst duration or average amplitude of the TLo with increasing steepness of downslope walking (fig. 3a). This was in contrast to the upslope condition (companion paper) where the burst duration and average amplitude increased with the slope. This finding was a bit surprising as it was assumed that this biarticular muscle would be contracting eccentrically during stance.

The one monoarticular muscle, brachialis (Br), with flexor function at the elbow joint had predominately swingrelated activity. The burst began at the end of stance as the paw was being unweighted and continued to be active for the flexion phase of swing (fig. 2b). There was no change in the burst duration of the $\mathrm{Br}$ with increasing steepness of downslope walking. However, the average burst amplitude increased significantly compared to level walking. The average burst amplitude of the $\mathrm{Br}$ increased from $48 \pm 27 \mathrm{mV}$ during level to $168 \pm 40 \mathrm{mV}$ during the $-50 \%$ grade (fig. $3 \mathrm{c}$, d). This increase was similar to that observed for upslope walking during the flexion phase of swing.

The two biarticular muscles, the cleidobrachialis (ClB) and $\mathrm{Bi}$, which have flexor function at the elbow joint and extensor function at the shoulder joint, had unique activation patterns during downslope walking. During level walking, their activity began immediately after PC and continued through part of the flexion phase of swing (fig. 2b). For the ClB muscle, the burst duration increased significantly from $148 \pm 115 \mathrm{~ms}$ during level walking to $341 \pm 84 \mathrm{~ms}$ during the $-50 \%$ grade (fig. $3 \mathrm{c}$ ). For the $\mathrm{Bi}$ muscle, the burst duration increased significantly from $183 \pm 89 \mathrm{~ms}$ during level walking to $365 \pm 96 \mathrm{~ms}$ during the $-50 \%$ grade (fig. 3c). Similar to upslope walking, there was no change in the average burst amplitude of the $\mathrm{ClB}$ and $\mathrm{Bi}$ with increasing steepness of the downslope walking (fig. 3d). However, unique activation patterns of $\mathrm{ClB}$ and $\mathrm{Bi}$ occurred in two places during stance. One of the unique activation patterns was a cocontraction with the monoarticular elbow extensors during E2 and another occurred while the shoulder was flexing and the elbow was extending during E3 of decline walking indicative of an eccentric contraction of the biarticular elbow flexors.

\section{Short-Term Effects of Nerve Transection and Surgical Repair}

For all three walking conditions, the shoulder and elbow joint kinematics of the forelimb changed at the P2wks time period following transection and repair (ta- bles 2,3$)$. However, to simplify the data set, only the $-50 \%$ grade of slope walking will be discussed. For a report on the joint kinematics of the shoulder and elbow with level, overground locomotion, please refer to the Results section under Level Walking Kinematics in the companion paper [Livingston and Nichols, 2015]. With the paralysis of TLo and Bi during the P2wks time frame, one would expect the kinematic and interjoint coordination changes to occur during the stance phase and at the beginning and termination of the swing phase of locomotion as this is the period during which the muscles were most active (fig. 2).

\section{Kinematic Adaptations to Downslope Walking}

The paralysis of the TLo resulted in a significant change in the angular position of the shoulder and the elbow joints during early stance of the $-50 \%$ grade walking (table 2).

Initially, 2 cats (NO3t and SL5t) refused to walk down the $-50 \%$ grade ramp, but began to perform with affection and food reward. However, at the P2wks time interval during $\mathrm{PC}$, the shoulder joint was significantly more extended and the elbow joint was significantly more flexed (table 2). In the control condition of $-50 \%$ grade of walking during E2, the shoulder joint yield (flexion) and the elbow joint yield (flexion) occurred in a one-to-one relationship indicated by a positive slope (fig. 4a). During the paralysis of the TLo, the shoulder and elbow yield still occurred together during E2; however, the slope of this line was less (more horizontal) indicating a greater elbow yield and little change in the shoulder yield (fig. 4b). At the P1mo time interval, as some of the EMG activity returned to the TLo muscle, the E2 phase slope relationship of the shoulder-elbow plot was still less than the control situation (fig. 4c). This persistent increase in elbow yield was in contrast to the $50 \%$ upslope condition (see Results section in the companion paper) in which the slope relationship of the shoulder-elbow plot during E2 returned to the control condition.

Paralysis of the Bi resulted in a significant change in the angular position of the shoulder during the entire gait cycle (table 3 ). During paralysis of the $\mathrm{Bi}$, the shoulder angular excursion during the $\mathrm{E} 1$ phase of swing was less than the control condition, and, as a result, the shoulder was more flexed (less extension) at PC (table 3), whereas the elbow joint position remained unchanged. Furthermore, during stance in the control condition, the Bi muscle was active eccentrically in the downslope condition during E3 (fig. 5a), controlling flexion at the shoulder and extension at the elbow. During paralysis of the $\mathrm{Bi}$, the 


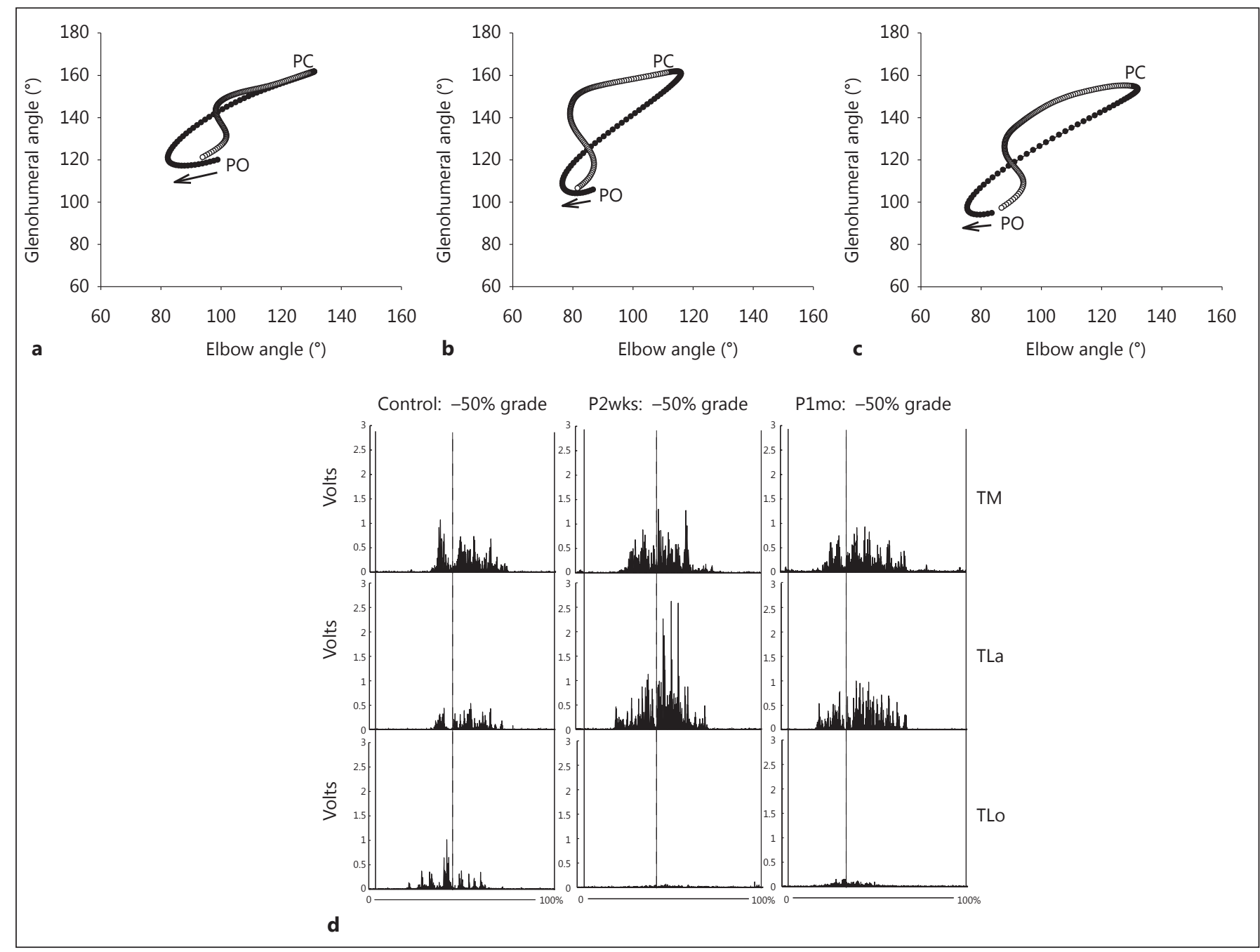

Fig. 4. Shoulder-elbow angle-angle plots and EMG for -50\% grade of walking (cat SL5t) following transection and repair of the radial nerve to the TLo. Values are the time-normalized averages of 10-
30 steps. a Control: $-50 \%$ grade $(\mathrm{n}=30)$. b P2wks: $-50 \%$ grade $(\mathrm{n}=10)$. c P1mo: $-50 \%$ grade $(\mathrm{n}=10)$. $\mathbf{d}$ Sample of the rectified EMG data during $-50 \%$ grade walking. shoulder was significantly more flexed (P2wks; table 3). At the P1mo time interval, the shoulder kinematics during swing and stance phases remained more flexed (less extended), and the elbow was more extended (less flexed; fig. 5b; table 3: P1mo).

\section{EMG Adaptations to Downslope Walking}

The adaptive EMG activity of the elbow extensor muscle group for $-50 \%$ grade walking which occurred during the TLo paralysis included both a significant increase in the burst duration and average amplitude of the monoarticular TM and TLa muscles (fig. 4d). The TM burst duration increased from $212 \pm 30 \mathrm{~ms}$ during the control condition to $299 \pm 73 \mathrm{~ms}$ during the TLo paralysis. The TLa burst duration increased from $193 \pm 28$ to $392 \pm 49 \mathrm{~ms}$, respectively. The TM average burst amplitude increased from $135 \pm 21 \mathrm{mV}$ during the control condition to $199 \pm$ $48 \mathrm{mV}$ during the TLo paralysis. The TLa average burst amplitude increased from $92 \pm 16$ to $258 \pm 56 \mathrm{mV}$, respectively. The difference between $50 \%$ upslope and $-50 \%$ downslope walking for the monoarticular elbow extensors was that during upslope walking they were undergoing a concentric (shortening) contraction and during downslope walking they were undergoing an eccentric (lengthening) contraction. However, they both significantly increased their burst duration and average amplitude apparently as an adaptation to the loss of function of the TLo. 


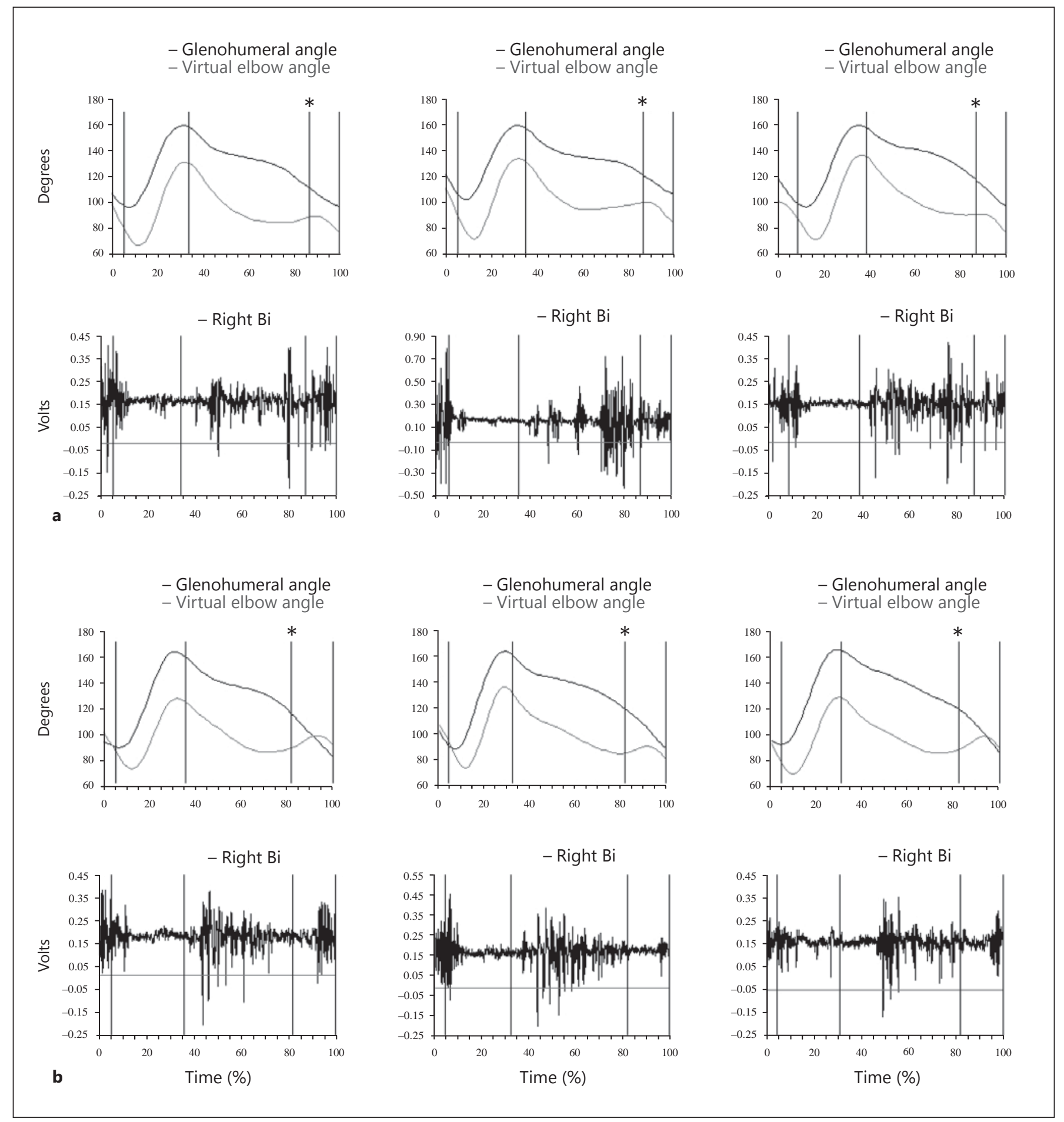

Fig. 5. Comparison of the shoulder and elbow angle-time plots and EMG adaptations in the Bi muscle group during $-50 \%$ grade downslope walking following Bi denervation for cat WL6b. a Example of three $-50 \%$ grade control trials showing active lengthen- ing contraction of the biceps $\left(^{*}\right)$. $\mathbf{b}$ Example of three $-50 \%$ grade P1mo time interval trials with loss of EMG activity during active lengthening $(*)$. 


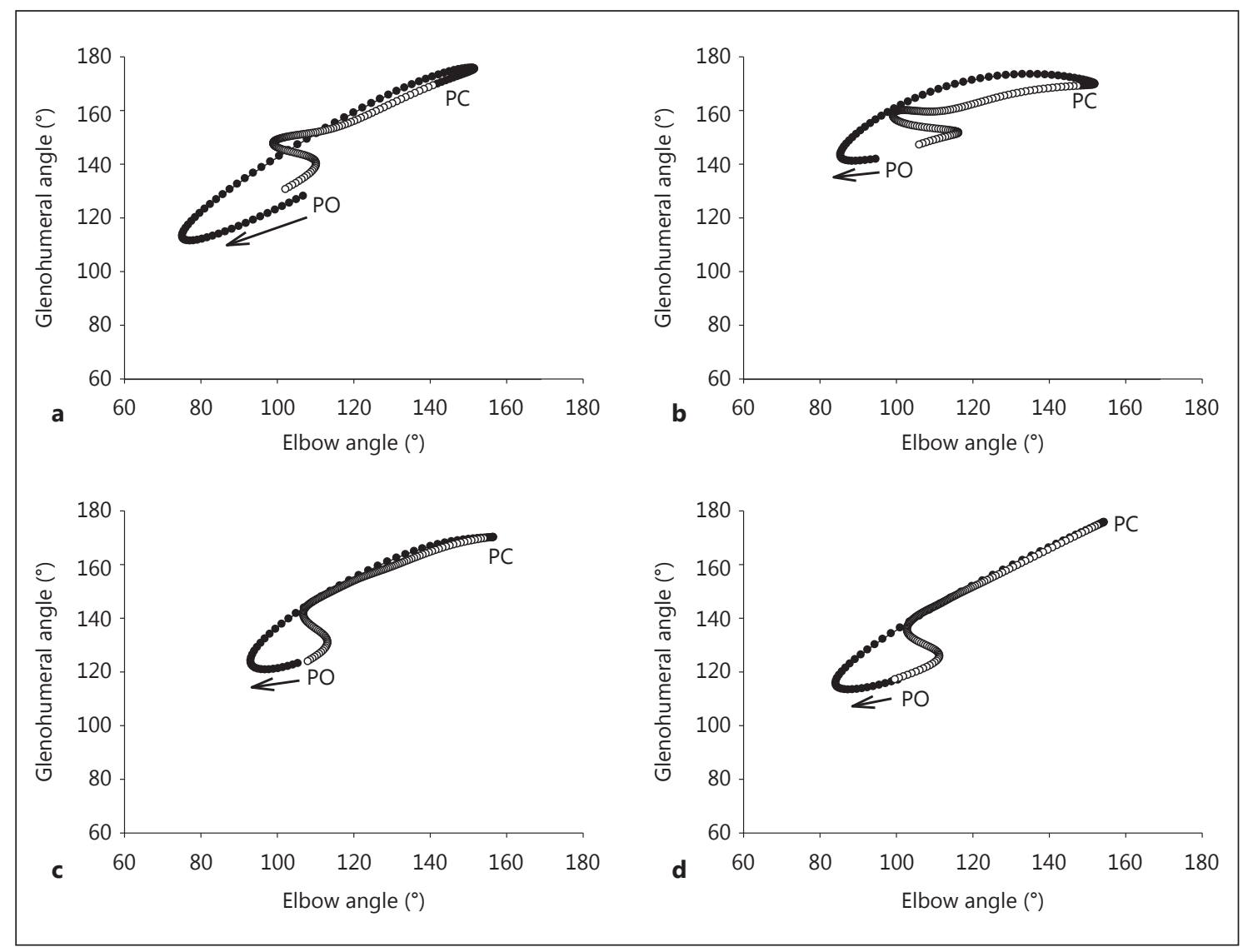

Fig. 6. Comparison of shoulder-elbow angle-angle plots between control and P12+mos for $-50 \%$ grade of walking following transection and repair of the TLo and Bi nerve. a Control: TLo reinnervation at $-50 \%$ grade for cat NO3t $(n=30)$. b P12+mos: TLo reinnervation $-50 \%$ grade for cat NO3t $(n=10)$. c Control: Bi reinnervation at $-50 \%$ grade for cat SM4b $(n=30)$. d P $12+$ mos: Bi reinnervation at $-50 \%$ grade for cat SM4b $(n=10)$.

The most notable change in EMG activity of the elbow flexor muscle group during Bi paralysis occurred during the end of stance (E3 phase). In the control condition, there was a period when the Bi muscle was active and the shoulder was flexing and the elbow was extending denoting an eccentric contraction (fig. 5a). However, as EMG activity returned in the Bi following paralysis, there was notable absence or attenuation of EMG signals during this period of active lengthening (fig. 5b). The window of the absent signal was approximately $20-40 \mathrm{~ms}$.

\section{Long-Term Effects of Reinnervation}

Kinematic Adaptations to Downslope Walking

In the control condition at the $-50 \%$ grade walking during the E2 phase of stance, the shoulder and elbow joint yield occurred in a one-to-one relationship indicated by a positive slope (fig. 6a). At the $\mathrm{P} 12+$ mos time interval (long-term effect) of TLo reinnervation, during the
E2 phase, the shoulder-elbow relationship remained similar to the denervation time point, as there was less of a positive slope and more of a horizontal line (fig. 6b).

The Bi muscle, which was active eccentrically in $-50 \%$ grade walking during the control condition of E3 (fig. 6c) controlling flexion at the shoulder and extension at the elbow, demonstrated an apparent lack of adaptation via the continued altered interjoint coordination (negative slope relationship of stance) during E3 at the P12+mos time interval (fig. 6d).

\section{EMG Adaptations to Downslope Walking}

Figure 7 illustrates the stance-related motor pattern of the biarticular shoulder extensors and elbow flexors (ClB and $\mathrm{Bi}$ ) which began after PC and continued until PO following the $\mathrm{P} 12+$ mos time interval of reinnervation of the $\mathrm{Bi}$. Similar to the short-term effects of paralysis of the $\mathrm{Bi}$ (fig. 5b), there was also a notable absence or attenuation 


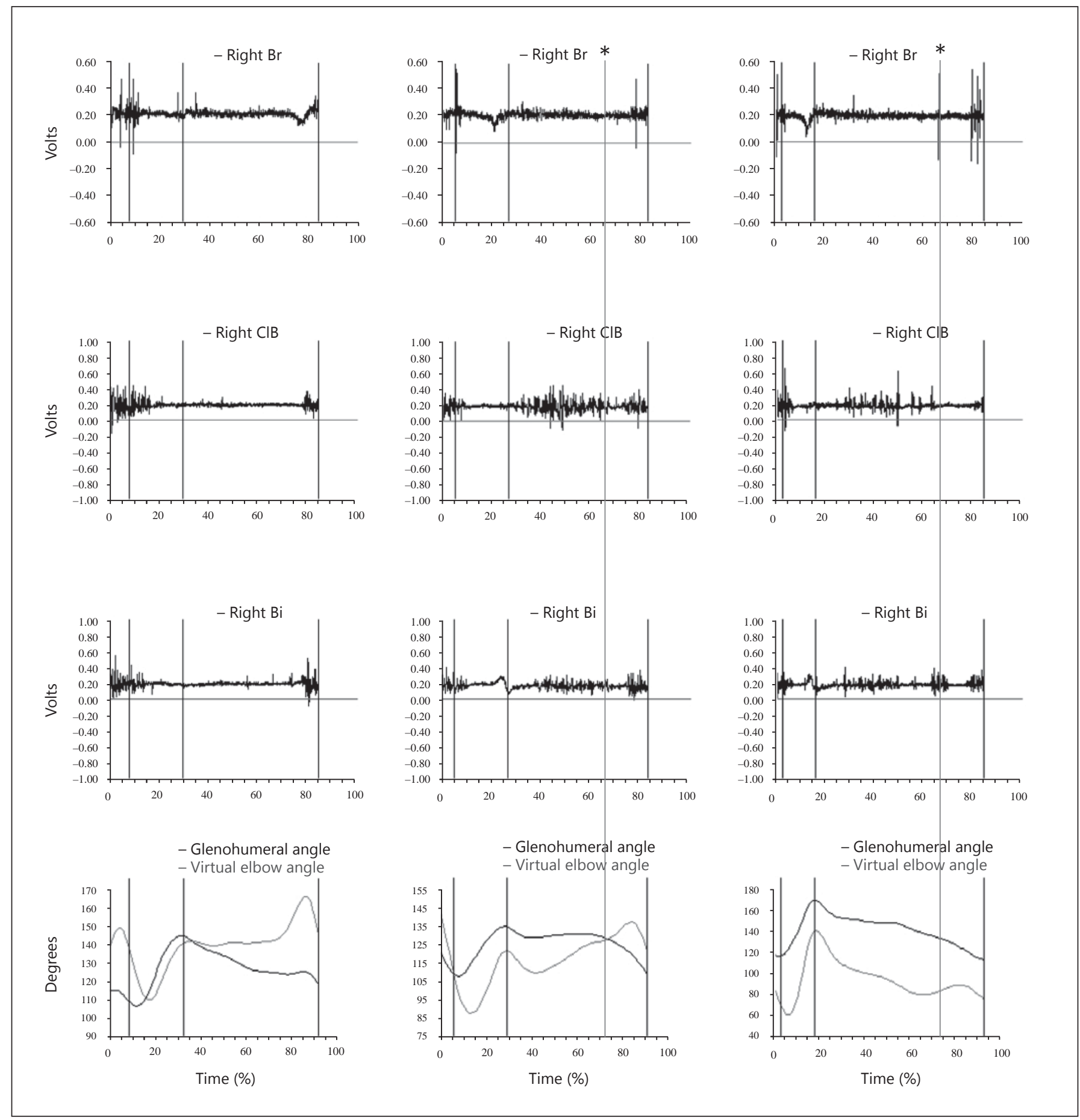

Fig. 7. Comparison of shoulder and elbow angle-time plots plus EMG adaptations between control and P12+mos for level (0\%) and downslope (-25 and $-50 \%)$ grades of walking following transec- tion and repair of the Bi nerve. Trials at P12+mos for cat SM4b $(\mathrm{n}=10){ }^{*}$ Active lengthening contraction by the biceps with loss of EMG activity. 
of EMG signals during the P12+mos time interval of active lengthening in $\mathrm{E} 3$ of the $-50 \%$ downslope walking (fig. 7).

\section{Effects of Reinnervation on Reflex Integrity}

The stretch reflex was lost or substantially reduced for the reinnervated TLo [Livingston and Nichols, 2015] and Bi (2 cats, data not shown).

\section{Discussion}

Four major findings resulted from this study. First, our results indicated that during downslope walking, there was an increasing shoulder and elbow yield (flexion) with grade. Second, there were two examples of eccentric contraction (active lengthening) acting to retard the forward pitch of the animal and to coordinate the shoulder and the elbow joints. The first was associated with activity in the monoarticular elbow extensors (TM and TLa) during E2 of stance and the second occurred with activity in the biarticular shoulder extensors and elbow flexors ( $\mathrm{ClB}$ and $\mathrm{Bi}$ ) during E3 of stance. These kinematics along with the corresponding forelimb motor patterns suggest that the eccentric contractions are providing an apparent 'braking' action which serves to control the effects of gravity and the movement of the animal's body down the walkway. Third, after 1 month of recovery and as some EMG activity had begun to return to the reinnervated muscles (TLo and $\mathrm{Bi}$ ), the kinematic and EMG adaptations did not return to the control condition. These data provide some insights into the role of the proximal forelimb muscles during downslope walking and the capacity of the motor system to adapt to their loss. Finally, as the reinnervated TLo and Bi muscles regained their efferent innervation while remaining without their short-latency stretch reflex, the shoulder-elbow kinematics for downslope locomotion remained altered during E2 for the TLo and during E3 (eccentric contraction) for the Bi, which yielded a more negative slope relationship and a partial loss of the Bi EMG signal.

\section{Slope-Related Changes in Forelimb Kinematics}

During quadrupedal downslope walking, there are different geometrical constraints and power requirements in order to accomplish this challenging task. The forelimb must be moved forward and placed on the incline such that the body mass can be moved forward, downward and over the forelimb during stance. Furthermore, although we have no kinetic data on the forelimb during downslope walking, we infer that the power requirements for upslope walking would be greater than during downslope walking in which the cat's mass is lowered in a controlled fashion.

During the swing phase of downslope walking, there were some unique relationships between the shoulder and elbow joints. First, in the beginning of swing at PO, there was no change in the shoulder position at the steeper grades, but the position of the elbow joint became more flexed. This change would be consistent with the elbow's contribution to power absorption and thus 'braking' during the very end of stance.

During E2, there was a progressive increase in the yield at the shoulder and elbow with the increasing grade of slope. This was expected if it was assumed that one would need more braking force and power absorption in the downslope conditions. This pattern of an increased yield was also noted in the feline ankle during downslope walking [Smith et al., 1998; Abelew et al., 2000] when braking and the muscle-tendon units of the gastrocnemius and soleus were actively lengthening [Gregor et al., 2006]. The transition from E2 to E3 (flexion to extension) occurred only at the elbow, no matter what the grade. This was also associated with eccentric work as the biarticular shoulder extensors and elbow flexors ( $\mathrm{ClB}$ and $\mathrm{Bi}$ ) were active, and the elbow extensors were silent. During this transition (E2-E3), the elbow joint was more flexed with the increasing grade of slope walking. Again, this is very consistent with the need for power absorption by the elbow in order to move the cat forward and downward.

\section{Motor Pattern Changes Associated with Downslope Walking}

Based on the assumption that the requirements for propulsion would be less and power absorption would be greater, we predicted that the elbow extensor activity would decrease over the range of grades tested. Our EMG data of the two monoarticular elbow extensors show that the recruitment of the TM and TLa were consistent with this prediction as the burst duration decreased at the $-50 \%$ grade. Furthermore, based on the similar mechanics of the hindlimb hip joint during downslope walking [Gregor et al., 2006], we predicted that the biarticular shoulder extensor and elbow flexor muscles ( $\mathrm{ClB}$ and $\mathrm{Bi}$ ) would be active during stance. Our EMG data of the two biarticular elbow flexors and the two monoarticular elbow extensors (TM and TLa) show that they were both active eccentrically during the stance phase.

The shoulder joint flexed throughout stance and the elbow flexed during most of stance in downslope walking. During E3 (late stance), the shoulder continues to flex 
and the elbow extends while the $\mathrm{ClB}$ and $\mathrm{Bi}$ were active. Because the shoulder was flexing and the elbow was extending in the face of a shoulder extensor and elbow flexor contraction, it is likely that power was absorbed as these muscles undergo a lengthening (eccentric) contraction. Similar conditions exist in the hip for the iliopsoas and rectus femoris during downslope walking [Smith et al., 1998] and backward walking [Perell et al., 1993]. These data suggest that the $\mathrm{ClB}$ and the Bi muscles retard the forward pitch of the animal due to the effects of gravity and momentum from moving down the walkway.

\section{Adaptations to Downslope Walking with Nerve \\ Transection and Surgical Repair}

A fundamental issue in the neuromuscular control of movement is the extent to which the nervous system is capable of choosing different muscle activity patterns to produce similar joint kinematics even in the face of different contractile conditions, such as active lengthening (eccentric contraction). In normal situations after learning a movement, subjects choose a similar muscle activation pattern with limited variability in the movement kinematics. Therefore, in order to test the capacity of the nervous systems to adapt and choose different activation patterns, the system must be challenged. Paralyzing a biarticular elbow extensor or flexor muscle and asking the animal to adapt to downslope locomotion is one way to evaluate the redundancy of the neuromuscular system. During progressive grades of downslope walking with paralysis of the TLo or the $\mathrm{Bi}$, the following adaptations occurred. First, the increase in burst amplitude of the monoarticular TM and TLa was not sufficient to compensate for the increased elbow yield even though they contributed to the extensor torque about the elbow. Eccentric contractions are typically thought to be more efficient [Kaneko et al., 1984; Enoka, 1996], yet these muscles were still unable to maintain the shoulder-elbow kinematics. One plausible explanation could lie in the multifunctionality of biarticular muscles.

In both humans and animals, mono- and biarticular muscles have been associated with unique functional roles [Kaya et al., 2005]. One advantage of biarticular muscles is that the force generated by one muscle could produce movement at two joints. Thus, biarticular muscles could be activated when the moments they produce about both joints are in concert with the actual movement [Gregor et al., 2001]. However, in this case the TLo is the only biarticular elbow extensor and the movements of the shoulder and the elbow are in opposite directions. Van Ingen Schenau et al. [1987, 1992, 1995] proposed that

Effects of Reinnervation of Feline Elbow

Muscles during Downslope Walking monoarticular muscles are activated when movement directions involve shortening, while biarticular muscles are activated to control the direction of external forces by adjusting the moments at the two joints they span. This could explain the inability of the monoarticular muscles, the TM and the TLa, to compensate without the TLo during early stance phase. However, in order to fully support this suggestion, further research is needed to record simultaneously the forces in the TLo and the external kinetics.

Another explanation for the lack of recovery of normal kinematics following paralysis of one synergist is the lack of intermuscular feedback from the biarticular TLo onto the synergistic, monoarticular TM and TLa. It appears from the recorded kinematics and EMG activation patterns that the motor control strategy was to move the center of mass of the cat gradually down the ramp in a controlled manner by utilizing a cocontraction of the monoarticular elbow extensors and biarticular elbow flexors to retard the forward pitch of the cat. This was also seen in the hindlimb following complete reinnervation of the triceps surae in the cat [Abelew et al., 2000; Maas et al., 2007] and at 4 and 10 weeks in the rat with sciatic nerve reinnervation [Sabatier et al., 2011].

Afferent input during slope walking might modulate muscle activation patterns differently from that during level walking because of the difference in mechanical conditions between the two tasks [Pearson, 2000a, b]. The unexpected results of Smith et al. [1998] concerning the increase in stance-related activity of the hip flexors (iliopsoas and rectus femoris) during downslope walking was consistent with the hip flexor and knee extensor moments during stance reported by Gregor et al. [2006]. Thus, it seems logical that muscles with elbow flexion action, such as the $\mathrm{Bi}$ and $\mathrm{ClB}$, were active during most of stance for downslope walking. In the hindlimb, during downslope walking, it was suggested that power would be absorbed at the hip joint during downslope stance as a flexor muscle torque coincided with hip extension [Winter and Robertson, 1978; Perell et al., 1993]. This would support another proposed function of biarticular muscles as isometric structures that transport mechanical energy from one joint to an adjacent joint rather than producing substantial work themselves [Jacobs et al., 1993].

Paralyzing the biarticular shoulder extensor and elbow flexor (Bi) activity during downslope walking resulted in changes in the kinematics of the shoulder and elbow that demonstrated a lack of control of the shoulder flexion and elbow extension that persists even when the EMG activity began to return in the $\mathrm{Bi}$. However, unexpectedly, 
there was a pause or absence of EMG signals associated during this eccentric activity as the reinnervation of the Bi proceeded, presumably due to the loss of critical proprioceptive feedback. The autogenic stretch reflex compensates for and enhances muscular stiffness [Nichols and Houk, 1976; Carter et al., 1990; Sinkjaer, 1997; Huyghues-Despointes et al., 2003a, b] and compensates for external (ground reaction forces) or internal (inertial compensations) disturbances. Muscle spindles respond asymmetrically, more to stretch than to release, thus the contribution to a muscle's EMG would be greater during stretch (lengthening contraction) than release (shortening contraction). The loss of this reflex in the reinnervated $\mathrm{Bi}$, along with the loss of EMG activity during E3 (eccentric contraction), suggests that part of the EMG activity may represent the loss of the autogenic stretch reflex during this voluntary motor activity. This unique finding about the forelimb biarticular flexor suggests an important role of reflex activity during eccentric contractions and in downslope walking. This unique finding is unlike what occurred in the hindlimb extensors during downslope walking, where there was both an increase in the load on the forelimb and lengthening of the Bi (flexor) taking place.

\section{Adaptations to Downslope Walking following \\ Reinnervation of the Biarticular Muscles}

A critical issue in the neuromuscular control of movement is the role and contribution of short-latency proprioceptive feedback from muscles. Stretch-evoked reflexes have been shown to contribute to the mechanical properties of muscles [Liddell and Sherrington, 1924; Nichols and Houk, 1976; Hoffer and Andreassen, 1981; Cordo and Rymer, 1982; Cope et al., 1994; HuyghuesDespointes et al., 2003a, b] and therefore regulating antigravity support during standing [Sherrington, 1906; Nichols, 2002] and locomotion [Pearson et al., 1999; Stein et al., 2000]. In the absence of reflex action, the joint would undergo increased yielding. In the presence of a stretch reflex, increased firing rate modulation and recruitment of new motor units maintain muscular stiffness and would prevent muscle and joint yielding. However, because muscles yield more during active lengthening than during shortening, intrinsic muscular stiffness is greater during a shortening contraction (concentric). The action of the stretch reflex results in a larger contribution of motor unit recruitment during active lengthening (eccentric) and tends to equalize net muscular stiffness in the two directions. It has also been suggested that in the absence of the stretch reflex, with a compromise in muscular stiffness regulation, there is a loss of interjoint coordination [Nichols, 1999; Abelew et al., 2000; Maas et al., 2007].

Further evidence of the importance of the stretch reflex in modulating muscle stiffness and the control of interjoint coordination lies in the loss or attenuation of EMG signals during the active lengthening of the reinnervated Bi muscle during downslope locomotion. In the hindlimb, it was suggested that the soleus muscle activity might depend more strongly on input from muscle spindle afferents during downslope walking [Gregor et al., 2006]. However, there is no report of the loss of EMG activity in the reinnervated soleus (a monoarticular muscle) during active lengthening of downslope walking. Furthermore, related to the hindlimb extensors, it was suggested that there are potential reflex combinations, such as both the stretch reflex and autogenic force feedback [Ross and Nichols, 2009], that could modulate the force output of active muscle.

Recently, studies by Haftel et al. [2005] and Bullinger et al. [2011] have provided some evidence of the mechanisms by which stretch reflexes fail to recover following nerve transection and repair. First, there is substantial structural disruption of the central monosynaptic connection between muscle spindle afferents and the a-motoneurons and, secondarily, synaptic excitation is reduced by misguided axon regeneration that reconnects afferents to the wrong receptor. This mechanism may underlie the attenuation of the biceps EMG signal following reinnervation.

\section{Technical Considerations}

Describing 3-dimensional kinematics of the shoulder joint utilizing external markers attached to the skin is confronted with some inherent problems, the least of which is skin slippage. Numerous other authors have used skin markers to characterize the behavior of the forelimb during overground and treadmill locomotion [Miller and Van Der Meché, 1975; English, 1978; Halbertsma, 1983]. More recently, the X-ray technique employed by Boczek-Funcke et al. [1996] yielded relatively similar angular excursions and velocity profiles at the glenohumeral joints compared to our data.

Because some of our conclusions are based on the measurements of EMG activity over a period of 2 weeks to 2 months, an important issue is the stability of the EMG recordings. It is possible that progressive changes in electrode position or the properties of the electrode could have contributed to the differences found in the EMG recordings during the short-term effects. There are several arguments against this explanation. One very compelling 
reason is the fact that during the recovery of TLo and $\mathrm{Bi}$ EMG activity, there was a difference in both duration and average amplitude during the P2wks time interval, which after 2 more weeks resulted in only the increased duration. Movement or physical change in the electrodes would be expected to alter both of these components similarly. Another argument was that these changes were not observed in a second cat that did not undergo the TLo or Bi reinnervation (data not shown). Furthermore, these changes were not observed in any of the other muscles which were recorded simultaneously.

\section{Conclusion}

During downslope walking, the body mass must be moved downward and forward aided by gravity as evident by the yielding (flexion) of both the shoulder and the elbow joints during stance. The more proximal forelimb muscles, the monoarticular TM and TLa and the biarticular $\mathrm{Bi}$, provide a braking force (eccentric contraction) during stance. We conclude that during the para- lytic stage, despite the acknowledged redundancy of the neuromuscular system, there is limited compensation for altered joint kinematics during downslope locomotion. Furthermore, the autogenic stretch reflex offers an important contribution to muscle stiffness and muscle activity during an active lengthening contraction such that occurs in the Bi muscle during E3 of downslope walking. We think these results add to the understanding of the effects of different mechanical conditions on afferent input and muscle activation patterns during a challenging mechanical condition such as downslope walking.

\section{Acknowledgments}

We would like to thank Arick Augang, Andrea Burgess, Brandon Buckner, Chris Chuong, Jinger Gottshall, Ginny LaMon, Melissa Miller, Gareth Nichols and Kyla Ross for their help in training and collecting data. We would also like to thank Boris Prilutsky and Robert Gregor for their help with making and implanting the EMG electrodes during the surgery, and Michael Boyles, graphic designer, for his assistance with the figures. This research was supported by NS 40405-03.

\section{References}

Abelew, T.A., M.D. Miller, T.C. Cope, T.R. Nichols (2000) Local loss of proprioception results in disruption of interjoint coordination during locomotion in the cat. J Neurophysiol 84 : 2709-2714.

-Alexander, R. (1980) Optimum walking techniques for quadrepeds and bipeds. J Zool 192: 97-117.

Boczek-Funcke, A., J.P. Kuhtz-Buschbeck, M. Illert (1996) Kinematic analysis of the cat shoulder girdle during treadmill locomotion: an X-ray study. Eur J Neurosci 8: 261-272.

Buford, J.A., J.L. Smith (1990) Adaptive control for backward quadrupedal walking. II. Hindlimb muscle synergies. J Neurophysiol 64: 756-766.

Bullinger, K.L., P. Nardelli, M.J. Pinter, F.J. Alvarez, T.C. Cope (2011) Permanent central synaptic disconnection of proprioceptors after nerve injury and regeneration. II. Loss of functional connectivity with motoneurons. J Neurophysiol 106: 2471-2485.

Carlson-Kuhta, P., T.V. Trank, J.L. Smith (1998) Forms of forward quadrupedal locomotion. II. A comparison of posture, hindlimb kinematics, and motor patterns for upslope and level walking. J Neurophysiol 79: 1687-1701.

-Carter, R.R., P.E. Crago, M.W. Keith (1990) Stiffness regulation by reflex action in the normal human hand. J Neurophysiol 64: 105-118.
Chang, Y.H., A.G. Auyang, J.P. Scholz, T.R. Nichols (2009) Whole limb kinematics are preferentially conserved over individual joint kinematics after peripheral nerve injury. J Exp Biol 212: 3511-3521.

Cope, T.C., S.J. Bonasera, T.R. Nichols (1994) Reinnervated muscles fail to produce stretch reflexes. J Neurophysiol 71: 817-820.

Cordo, P.J., W.Z. Rymer (1982) Contributions of motor-unit recruitment and rate modulation of compensation for muscle yielding. J Neurophysiol 47: 797-809.

English, A.W. (1978) An electromyographic analysis of forelimb muscles during overground stepping in the cat. J Exp Biol 76: 105-122.

-Enoka, R.M. (1996) Eccentric contractions require unique activation strategies by the nervous system. J Appl Physiol 81: 2339-2346.

Fowler, E.G., R.J. Gregor, J.A. Hodgson, R.R. Roy (1993) Relationship between ankle muscle and joint kinetics during the stance phase of locomotion in the cat. J Biomech 26: 465-483.

Gregor, R., D. Smith, B. Prilutsky (2006) Mechanics of slope walking in the cat: quantification of muscle load, length change and ankle extensor EMG patterns. J Neurophysiol 95: 1397-1409.

Gregor, R.J., J.L. Smith, D.W. Smith, A. Oliver, B.I. Prilutsky (2001) Hindlimb kinetics and neural control during slope walking in the cat: unexpected findings. J Appl Biomech 17: $277-286$.
Haftel, V.K., E.K. Bichler, Q.B. Wang, J.F. Prather, M.J. Pinter, T.C. Cope (2005) Central suppression of regenerated proprioceptive afferents. J Neurosci 25: 4733-4742.

- Halbertsma, J. (1983) The stride cycle of the cat: the modeling of locomotion by computerized analysis of automatic recordings. Acta Physiol Scand Suppl 521: 1-75.

Hoffer, J.A., S. Andreassen (1981) Regulation of soleus muscle stiffness in premammillary cats: intrinsic and reflex components. J Neurophysiol 45: 267-285.

Huyghues-Despointes, C.M.J.I., T.C. Cope, T.R. Nichols (2003a) Intrinsic properties and reflex compensation in reinnervated triceps surae muscles of the cat: effect of activation level. J Neurophysiol 90: 1537-1546.

Huyghues-Despointes, C.M.J.I., T.C. Cope, T.R. Nichols (2003b) Intrinsic properties and reflex compensation in reinnervated triceps surae muscles of the cat: effect of movement history. J Neurophysiol 90: 1547-1555.

Jacobs, R., M.F. Bobbert, G.J. van Ingen Schenau (1993) Function of mono- and biarticular muscles in running. Med Sci Sports Exerc 25: 1163-1173.

Kaneko, M., P.V. Komi, O. Aura (1984) Mechanical efficiency on concentric and eccentric exercise performed with medium to fast contraction rates. Scan J Sports Sci 6: 15.
Effects of Reinnervation of Feline Elbow Muscles during Downslope Walking 
Kaya, M., A. Jinha, T.R. Leonard, W. Herzog (2005) Multi-functionality of the cat medical gastrocnemius during locomotion. J Biomech 38: 1291-1301.

Liddell, E.G.T., C. Sherrington (1924) Reflexes in response to stretch (myotatic reflexes). Proc $\mathrm{R}$ Soc Lond B Biol Sci 96: 212-242.

Livingston, B.P., T. A. Abelew, T.R. Nichols (2004) Kinematic analysis of visually guided reaching in denervated and reinnervated biceps and triceps of the feline forelimb. San Diego, Society for Neuroscience.

Livingston, B.P., Y.H. Chang, T.A. Abelew, T.R. Nichols (2002) Kinematic analysis of the feline forelimb during level and slope walking and visually guided reaching. Orlando, Society for Neuroscience.

Livingston, B.P., T.R. Nichols (2005) Kinematic and EMG analysis of feline forelimb during the swing phase of slope walking and visually guided reaching. Washington, Society for Neuroscience (on-line program No 989.12).

Livingston, B.P., T.R. Nichols (2015) Effects of reinnervation of the triceps brachii on joint kinematics and electromyographic patterns of the feline forelimb during level and upslope walking. Cells Tissues Organs DOI: 10.1159/000371543.

Maas, H., R.J. Gregor, E.F. Hodson-Tole, B.J. Farrell, B.I. Prilutsky (2009) Distinct muscle fascicle length changes in feline medial gastrocnemius and soleus muscles during slope walking. J Appl Physiol 106:1169-1180.

-Maas, H., B.I. Prilutsky, T.R. Nichols, R.J. Gregor (2007) The effects of self-reinnervation of cat medial and lateral gastrocnemius muscles on hindlimb kinematics in slope walking. Exp Brain Res 181: 377-393.

Manter, J.T. (1938) The dynamics of quadrupedal walking. J Exp Biol 15: 522-540.

-Miller, S., F. Van Der Meché (1975) Movements of the forelimbs of the cat during stepping on a treadmill. Brain Res 91: 255-269.

-Nichols, T.R. (1987) A technique for measuring the mechanical actions of heterogenic (intermuscular) reflexes in the decerebrate cat. J Neurosci Methods 21: 265-273.

- Nichols, T.R. (1989) The organization of heterogenic reflexes among muscles crossing the ankle joint in the decerebrate cat. J Physiol 410: 463-477.

Nichols, T.R. (1994) A biomechanical perspective on spinal mechanisms of coordinated muscular action: an architecture principle. Acta Anat (Basel) 151: 1-13.
Nichols, T.R. (1999) Receptor mechanisms underlying heterogenic reflexes among the triceps surae muscles of the cat. J Neurophysiol 81: 467-478.

Nichols, T.R. (2002) Musculoskeletal mechanics: a foundation of motor physiology. Adv Exp Med Biol 2002;508:473-479.

Nichols, T.R., J.C. Houk (1976) Improvement in linearity and regulation of stiffness that results from actions of stretch reflex. J Neurophysiol 39: 119-142.

Pandy, M., V. Kumar, N. Berme, K. Waldron (1988) The dynamics of quadrupedal locomotion. J Biomech Eng 110: 230-237.

- Pearson, K. (2000a) Neural adaptation in the generation of rhythmic behavior. Annu Rev Physiol 62: 723-753.

Pearson, K. (2000b) Plasticity of neuronal networks in the spinal cord: modifications in response to altered sensory input. Prog Brain Res 128: 61-70.

Pearson, K.G., K. Fouad, J.E. Misiaszek (1999) Adaptive changes in motor activity associated with functional recovery following muscle denervation in walking cats. J Neurophysiol 82 : 370-381.

Perell, K.L., R.J. Gregor, F.A. Buford, J.L. Smith (1993) Adaptive control for backward quadrupedal walking. IV. Hindlimb kinetics during stance and swing. J Neurophysiol 70: 2226-2240.

Philippson, M. (1905) L'autonomie et la centralisation dans le système nerveux des animaux. Bruxelles, Falk.

Prilutsky, B.I., M.G. Sirota, R.J. Gregor, I.N. Beloozerova (2005) Quantification of motor cortex activity and full-body biomechanics during unconstrained locomotion. J Neurophysiol 94: 2959-2969.

Ross, K.T., T.R. Nichols (2009) Heterogenic feedback between hindlimb extensors in the spontaneously locomoting premammillary cat. J Neurophysiol 101: 184-197.

Rossignol, S. (1996) Handbook of Physiology. New York, American Physiological Society.

Sabatier, M.J., B.N. To, J. Nicolini, A.W. English (2011) Effect of slope and sciatic nerve injury on ankle muscle recruitment and hindlimb kinematics during walking in the rat. J Exp Biol 214: 1007-1016.

-Sherrington, C.S. (1906) Observations on the scratch-reflex in the spinal dog. J Physiol 34: $1-50$.
Sinkjaer, T. (1997) Muscle, reflex and central components in the control of the ankle joint in healthy and spastic man. Acta Neurol Scand Suppl 170: 1-28.

Smith, J., P. Carlson-Kuhta, T. Trank (1998) Forms of forward quadrupedal locomotion. III. A comparison of posture, hindlimb kinematics, and motor patterns for downslope and level walking. J Neurophysiol 79: 17021716.

Smith, J., S. Chung, R. Zernicke (1993) Gait-related motor patterns and hindlimb kinetics for the cat trot and gallop. Exp Brain Res 94: 308322

Stein, P.S.G., D.G. Stuart, S. Grillner, A.I. Selverston (1997) Neurons, Networks, and Motor Behaviour, ed 1. Cambridge, MIT Press.

-Stein, R., J. Misiaszek, K. Pearson (2000) Functional role of muscle reflexes for force generation in the decerebrate walking cat. J Physiol 525 (3): 781-791.

Trank, T.V., C. Chen, J.L. Smith (1996) Forms of forward quadrupedal locomotion. I. A comparison of posture, hindlimb kinematics, and motor patterns for normal and crouched walking. J Neurophysiol 76: 2316-2326.

Trank, T.V., J.L. Smith (1996) Adaptive control for backward quadrupedal walking. VI. Metatarsophalangeal joint dynamics and motor patterns of digit muscles. J Neurophysiol 75: 678-679.

van Ingen Schenau, G., M. Bobbert, R. Rozendal (1987) The unique action of bi-articular muscles in complex movements. J Anat 155: 1-5.

van Ingen Schenau, G., P. Boots, G. de Groot, R. Snackers, W. van Woensel (1992) The constrained control of force and position in multi-joint movements. Neuroscience 46 : 197-207.

van Ingen Schenau, G., W. Dorssers, T. Welter, A. Beelen, G. de Groot, R. Jacobs (1995) The control of mono-articular muscles in multijoint leg extensions in man. J Physiol 484: 247-254.

Winter, D., D. Robertson (1978) Joint torque and energy patterns in normal gait. Biol Cybern 29: $137-142$.

Zernike, R.F., J.L. Smith (1996) Biomechanical insights into neural control of movement; in Rowell, L.B., J.T. Shepherd (eds): Handbook in Physiology: Exercise, Regulation and Integration of Multiple Systems. New York, Oxford University Press, p 293. 